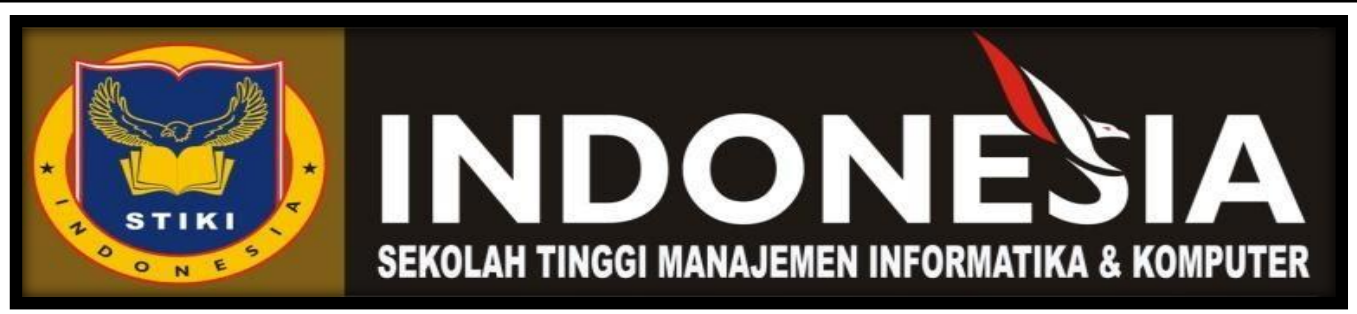

\title{
Analisis Video Views to Video Like Ratio Tiktok Pada 5 Artis Tik Tok dengan Followers Terbanyak
}

I Putu Hendika Permana, S.Kom., M.M.

hendika@stiki-indonesia.ac.id

NAMA

: DANIEL DIMETRIUS LONGA RANI

KELAS $\quad:$ AD

NIM

: 17101777 


\begin{abstract}
ABSTRAK
Semakin banyaknya pengguna media sosial TikTok pada remaja di Indonesia tentu akan berpengaruhterhadap salah satu tahap perkembangan remaja yakni mengenai kepercayaan diri. Memiliki kepercayaan diri sangat penting hal ini dikarenakan seorang remaja akan mampu untuk menilai diri sendiri danmelakukan suatu pekerjaan secara efektif di dalam kehidupannya. Penelitian ini menggunakan metodepenelitian kuantitatif dengan paradigma positivistik. Pengumpulan data dilakukan dengan cara penyebarankuesioner sesuai dengan kriteria sampel yang telah ditentukan. Sampel pada penelitian kali ini yakni remajadengan usia 15-19 tahun di Kabupaten Sampang. Tinjauan pustaka ini dimulai mengenai penggunaan mediasosial TikTok sampai pengaruhnya terhadap kepercayaan diri remaja yang kemudian berhubungan denganteori uses and gratification. Teori ini menjelaskan mengenai konsekuensi keterlibatan individu secara aktifmaupun kurang aktif dalam media. Setiap individu memiliki tingkat kebutuhan yang berbeda dalammenggunakan media. Salah satu kebutuhan yang ingin dipenuhi seseorang yakni mengenai peningkatankepercayaan diri. Penelitian ini menggunakan analisis regresi linier sederhana. Hasil penelitianmengungkapkan bahwa terdapat pengaruh yang signifikan dari penggunaan media sosial TikTok terhadap kepercayaan diri remaja sebesar 54,5\%.
\end{abstract}

Kata kunci : Media Sosial TikTok, Kepercayaan Diri, dan Teori Uses and Gratification.

\begin{abstract}
The growing number of TikTok social media users in mid teens in Indonesia will certainly affect the task ofadolescent development regarding self-confidence. Having self-confidence is very important because ateenager will be able to judge himself and do a job effectively. This study uses quantitative research methods with a positivistic paradigm. Data collection was carried out by distributing questionnaires according tothe sample criteria that had been done. The sample in this study is adolescents aged 15-19 years in SampangRegency. This literature review starts with the use of TikTok social media to its influence on adolescent selfconfidence to the uses and gratification theory that provides an understanding of the consequences of activeand less active involvement of individuals in consuming media to the explanation of the need for increasedselfconfidence. This research uses simple linear regression analysis. The results revealed that there was asignificant effect of the use of TikTok social media on adolescent self confidence of 54.5\%.
\end{abstract}

Keywords: TikTok Social Media, Self Confidence, and Theory of Uses and Gratification. 


\section{PENDAHULUAN}

Tik Tok merupakan salah satu aplikasi yang paling terpopuler dan diminati di dunia.Tik Tok memungkinkan penggunanya membuat video berdurasi 15 detik disertai musik, filter, dan beberapa fitur kreatif lainnya. Aplikasi ini diluncurkan oleh perusahaan asal Tiongkok, China, ByteDance pertama kali meluncurkan aplikasi yang memiliki durasi pendek yang bernama Douyin. Hanya dalam waktu 1 tahun, Douyin memiliki 100 juta pengguna dan 1 miliar tayangan video setiap hari. Popularitas Douyin yang tinggi membuatnya melakukan perluasan ke luar China dengan nama Tik Tok. Menurut laporan dari Sensor Tower,aplikasi ini diunduh 700 juta kali sepanjang tahun 2019. Hal ini membuat Tik Tok dapat mengungguli sebagian aplikasi yang berada dibawah naungan Facebook Inc. aplikasi ini menempati peringkat ke dua setelah Whatsapp yang memiliki 1,5 miliar pengunduh (Kusuma, 2020). Di Indonesia Pada tahun 2018 aplikasi ini dinobatkan sebagai aplikasi terbaik di Play store yang dimiliki oleh Google. Tidak hanya itu, Tik Tok juga menjadi kategori aplikasi paling menghibur (Imron, 2018). Pada Juli lalu Aplikasi buatan China itu sempat diblokir oleh Kementrian Komunikasi dan Informatika (Kominfo) di pertengahan 2018, alasannya karena adanya konten-konten yang negatif, terutama bagi anak-anak. Pemblokiran pada aplikasi ini hanya berlangung seminggu, mulai 3-10 Juli 2018. (Kusuma, 2020).(Akademi Komunikasi BSI Jakarta, 2018)(Akademi Komunikasi BSI Jakarta, 2018)

Kehadiran media sosial TikTok dapat membangun sebuah brand, TikTok juga dapat membangun personal branding pemiliknya (Ishihara and Oktavianti 2021). Di Indonesia, terdapat 30,7 juta pengguna TikTok yang aktif sehingga menjadikan Indonesia sebagai negara dengan pengguna TikTok terbesar di dunia. Maraknya jumlah pengguna TikTok ini sendiri dapat kita liat tentunya dari jumlah followers yang dimiliki oleh beberapa pengguna TikTok.Untuk indonesia sendiri penggunanya sangat banyak bahkan hampir semuanya menggunakan TikTok dengan alasan yang beragam. Dari banyaknya pengguna tentunya akan ada yang menjadi artis TikTok dengan folowers/pengikut terbanyak. Di indonesia pengikut terbanyak atau dalam dunia TikTok biasa disebut TikTokkers dipimpin oleh Sandys.ss, Cahyanirynn, .Ria Ricis,Jharna Bhagwani dan Saalhaerid. Penelitian ini menggunakan metode eksploratif kuantitatif, dan akan menghitung menggunakan rasio-rasio yang ada pada TikTok. Pada penelitian (Permana and Meinarni 2021) menjelaskan bahwa terdapat 17 rasio yang ada pada sosial media TikTok dan relevan digunakan sebagai media ukur kredibilitas akun yang ada. Penelitian ini hanya berfokus untuk menghitung kredibilitas Video Views to Video Like Ratio pada Top 5 Artis TikTok di Indonesia. Adapun Tujuan dari penelitian ini adalah mengetahui kredibilitas performa dari akun Artis TikTok di Indonesia menggunakan Video Views to Video Like Ratio.(Oktaheriyani et al., 2020) 


\section{TINJAUAN PUSTAKA}

Aplikasi ini awalnya bukanlah bernama Tik Tok. Aplikasi ini juga tidak berada di negara lain kecuali China. Dulu nama aplikasi ini adalah Douyin dimana penggunanya dapat membagikan video pendek dengan durasi 15 detik ke pada seluruh pengguna.

Tetapi ternyata, di sinilah sejarah Tik Tok di dunia dimulai. Douyin meraup keuntungan yang cukup besar di China dengan jumlah pengguna mencapai 100 juta orang hanya dalam waktu setahun. Oleh karena itu, perusahaan ByteDance memiliki ide yang cukup besar, yakni memperkenalkan aplikasi ini kepada Dunia.

Tik Tok aplikasi buatan China ini memang sudah mendulang kesuksesan besar. Bahkan sudah banyak endorsement yang memanfaatkan aplikasi ini untuk mempromosikan produknya. Oleh itu, tidak heran jika Tik Tok mulai membuka program bernama Tik Tok Ads.

Tetapi sejarah aplikasi Tik Tok yang Mendunia bukan hanya sampai di sini. Perusahaan yang menaungi Tik Tok sekarang bahkan berhasil mengakuisisi Musical.ly pada akhir 2017. Ini membuat di Tik Tok ada banyak lagu dan musik yang bisa dimaksimalkan oleh penggunanya.

Berawal dari aplikasi Douyin yang dibuat untuk konsumsi masyarakat China, kini Tik Tok telah berhasil menginvasi dunia. Di Indonesia sendiri, popularitas Tik Tok sudah tidak diragukan lagi. Ada banyak video lucu kreatif yang tersebar di Tik Tok dan juga merambah ke Instagram.(Akademi Komunikasi BSI Jakarta, 2018)

Syukurnya meskipun sempat diblokir di Indonesia karena dianggap tidak mendidik, kini Tik Tok kembali aktif. Kreator Tik Tok dari Indonesia juga sudah menyajikan beberapa fakta menarik dan ilmu bermanfaat melalui aplikasi tersebut. Itulah sejarah aplikasi Tik Tok yang Mendunia. 


\section{METODE PENELITIAN}

menggunakan metode eksploratif kuantitatif untuk mengetahui kredibilitas dari performa akun TikTok 5 Artis Indonesia. 5 Artis tersebut yaitu Sandys.ss, Cahyanirynn, .Ria Ricis,Jharna Bhagwani dan Saalhaerid.

Tujuan dari penelitian ini yaitu mengetahui nilai kredibillitas dari performa akun Tik Tok 5 Artis di Indonesia. Berikut adalah langkah langkah yang penliti gunakan untuk mengetahui performa terbaik dan peringkat terbaik dari kelima artis tik tok dengan followers terbanyak di indonesia.

1. Mencari pada website tentang $\mathbf{5}$ artis yang mendominasi Tik Tok untuk dianalisa Saya mencari pada website yang benar benar dipercaya dan pasti infonya. Setelah saya mendapatkan 5 akun artis tik tok dari website maka saya siap menganalisa.

2. Menghitung Nilai Rata-Rata Variabel Dari 5 Akun Tik Tok di Indonesia Pada bagian ini peneliti menghitung nilai variable VIDEO VEWS dan VIDEO LIKE. Menhitung nilai variabel ialah dengan mengambil 10 postingan terakhir dari setiap akun dan menghitung hingga menemukan nilai rata rata dari tiap akun artis tik tok tersebut.

\section{Menghitung Nilai Kredibilitas Rasio}

Menghitung nilai kredibilitas dari video views to video like ratio, dengan cara membagi nilai variabel pertama dan kedua. Misalnya video views 20 dan video like 10 maka cara kita menghitungnya ialah 20:10 $=2$. Maka video vews to video like adalah 2 .

\section{Menentukan Peringkat Pada Akun TikTok}

Pada penentuan peringkat harus melihat karakteristik dari rasio yang di teliti. Jika karakteristik rasio merupakan rendah, maka objek yang memiliki nilai terendah akan mendapatkan angka 5 dan objek yang memiliki nilai tertinggi akan mendapatkan angka 1. Namun jika rasio memiliki karakteritik tinggi maka objek yang mendapatkan nilai tinggi akan mendapatkan angka 5 dan objek yang mendapatkan nilai terendah akan mendapatkan angka 1. Setelah mendapatkan hasil kredibilitas ratio maka dapat disimpulkan objek yang mana mendapatkan peringkat 1 sampai dengan peringkat 5 . 


\section{HASIL DAN PEMBAHASAN}

5 Artis TIK TOK dengan followers terbanyak diantaranya ialah :

\section{Sandys.ss}

Pria bernama lengkap Sandy Saputra ini memiliki lebih dari 13 juta followers di TikTok. Ia juga sempat dinobatkan sebagai pengguna TikTok dengan followers terbanyak di tahun 2020. Selain itu, Sandy juga telah memiliki 330.2 juta likes di akun pribadinya.

Sumber : https://www.suara.com/entertainment/2021/05/27/095034/5-artis-tiktok-dengan-followers-terbanyak2021 ?page $=$ all

\section{Cahyanirynn}

Perempuan bernama lengkap Mega Dwi Cahyani ini memiliki hampir 12 juta followers di TikTok. Wanita yang akrabb disapa Caca ini lahir pada 1 September 1999. Selain terkenal di TikTok, Caca juga memiliki akun Youtube dengan 3.63 juta subscribers

Sumber : https://www.suara.com/entertainment/2021/05/27/095034/5-artis-tiktok-dengan-followers-terbanyak2021 ?page $=$ all

\section{Ria Ricis}

Selebgram yang juga Youtuber Indonesia ini menduduki peringkat ketiga sebagai pemilik followers TikTok terbanyak dengan jumlah lebih dari 10 juta followers serta 224.7 juta likes. Sebelumnya, Ria Ricis dikenal sebagai Youtuber dengan hampir 24 juta subscriber.

Sumber : https://www.suara.com/entertainment/2021/05/27/095034/5-artis-tiktok-dengan-followers-terbanyak2021 ?page $=$ all

\section{Jharna Bhagwani}

Sosok Jharnabhagwani pastilah sangat familiar di telinga pengguna TikTok atau makeup enthusiast. Hingga kini ia tercatat memiliki 9.5 juta followers dengan 116,8 likes. Perempuan berusia 18 tahun ini selalu mengunggah konten-konten makeup yang menarik dan berbeda.

Sumber : https://www.suara.com/entertainment/2021/05/27/095034/5-artis-tiktok-dengan-followers-terbanyak2021 ?page $=$ all

\section{Saalhaerid}

Saalhaerid menempati urutan kelima sebagai artis TikTok dengan followers terbanyak yakni hampir 10 juta followers. Ia kerap membagikan momen spesialnya bersama pasangan dan menjadikan keduanya sebagai couple goals oleh para pengikutnya.

Sumber : https://www.suara.com/entertainment/2021/05/27/095034/5-artis-tiktok-dengan-followers-terbanyak2021 ?page $=$ all 
Dari kelima Artis TikTok dengan followers terbanyak diatas, peneliti menemukan nilai dari masing-masing variabel yang ada untuk menghitung rasio views to like dari setiap Artis. Pada akun TikTok terdapat 7 variabel, diantaranya yaitu :

- Video Likes

- Video Comments

- Video Share

- Video Views

Dari kelima variabel tersebut peneliti hanya fokus menemukan hasil dari 2 variabel, yaitu :

- Video Views

- Video Like

Dari kedua variabel tersebut kemudian dianalisa sehingga menemukan nilai rata-rata dari variabel video views dan variabel video like. Untuk menghitung nilai rata-rata dari variabel video views dan variabel video like yaitu dengan cara mengambil minimal 10 postingan kemudian di hitung sehingga menemukan nilai rata-rata dari masing-masing variabel. Berikut merupakan tabel nilai rata-rata dari masing-masing Artis tik tok, yaitu :

Sumber : Pengolah Data Excel

1. Sandys.ss (13 juta followers)

\begin{tabular}{|c|cc|}
\hline NO & V.LIKE & V.VIEWS \\
\hline 1 & 300,000 & $1,000,000$ \\
\hline 2 & 200,000 & $2,000,000$ \\
\hline 3 & 300,000 & $3,000,000$ \\
\hline 4 & 100,000 & $1,000,000$ \\
\hline 5 & 150,000 & $2,000,000$ \\
\hline 6 & 200,000 & $1,000,000$ \\
\hline 7 & 212,000 & $4,000,000$ \\
\hline 8 & 100,000 & $1,000,000$ \\
\hline 9 & 98,000 & $1,000,000$ \\
\hline
\end{tabular}




\begin{tabular}{|c|rr|}
10 & 100,000 & $2,000,000$ \\
\hline TOTAL & 176,000 & $1,800,000$ \\
\hline
\end{tabular}

2. Cahyanirynn (12 juta followers)

\begin{tabular}{|c|cc|}
\hline NO & V.LIKE & V.VIEWS \\
\hline 1 & 100,000 & $1,000,000$ \\
\hline 2 & 100,000 & $1,000,000$ \\
\hline 3 & 30,000 & $3,000,000$ \\
\hline 4 & 100,000 & $1,000,000$ \\
\hline 5 & 150,000 & $2,000,000$ \\
\hline 6 & 210,000 & $1,000,000$ \\
\hline 7 & 212,000 & $1,000,000$ \\
\hline 8 & 100,000 & $1,000,000$ \\
\hline 9 & 90,000 & 90,000 \\
\hline 10 & 100,000 & $2,000,000$ \\
\hline TOTAL & 119,200 & $1,309,000$ \\
\hline & & \\
\hline
\end{tabular}

3. Ria Ricis ( $\mathbf{1 0}$ juta followers)

\begin{tabular}{|c|cc|}
\hline NO & V.LIKE & V.VIEWS \\
\hline 1 & 79,000 & 900,000 \\
\hline 2 & 17,900 & 700,000 \\
\hline 3 & 80,000 & 600,000 \\
\hline 4 & 100,000 & 400,000 \\
\hline 5 & 150,000 & $2,000,000$ \\
\hline
\end{tabular}




\begin{tabular}{|c|rr|}
\hline 6 & 23,000 & $1,000,000$ \\
\hline 7 & 212,000 & $1,000,000$ \\
\hline 8 & 100,000 & $1,000,000$ \\
\hline 9 & 77,000 & $1,000,000$ \\
\hline 10 & 100,000 & $2,000,000$ \\
\hline TOTAL & 93,890 & $1,060,000$ \\
\hline
\end{tabular}

4. Jharna Bhagwani (9,5 juta followers)

\begin{tabular}{|c|c|c|}
\hline NO & V.LIKE & V.VIEWS \\
\hline 1 & 20,000 & $4,000,000$ \\
\hline 2 & 19,000 & $2,000,000$ \\
\hline 3 & 99,000 & $2,000,000$ \\
\hline 4 & 111,000 & $1,000,000$ \\
\hline 5 & 150,000 & $2,000,000$ \\
\hline 6 & 20,000 & $1,000,000$ \\
\hline 7 & 212,000 & $1,000,000$ \\
\hline 8 & 100,000 & $1,000,000$ \\
\hline 9 & 50,000 & 500,000 \\
\hline 10 & 200,000 & $2,000,000$ \\
\hline TOTAL & 98,100 & $1,650,000$ \\
\hline
\end{tabular}


5. Saalhaerid (9 juta followers)

\begin{tabular}{|c|cr|}
\hline NO & V.LIKE & V.VIEWS \\
\hline 1 & 300,000 & $1,000,000$ \\
\hline 2 & 200,000 & $2,000,000$ \\
\hline 3 & 300,000 & $4,000,000$ \\
\hline 4 & 300,000 & $3,000,000$ \\
\hline 5 & 50,000 & $2,000,000$ \\
\hline 6 & 20,000 & $1,000,000$ \\
\hline 7 & 212,000 & $1,000,000$ \\
\hline 8 & 100,000 & $1,000,000$ \\
\hline 9 & 98,000 & $1,000,000$ \\
\hline 10 & 100,000 & $1,000,000$ \\
\hline TOTAL & 168,000 & $1,700,000$ \\
\hline
\end{tabular}


Setelah menghitung nilai rata-rata tersebut, maka akan menemukan hasil akhir nilai rata-rata dari variabel video views dan like

TABEL NILAI MASING MASING VARIABLE

\begin{tabular}{|l|r|c|c|c|c|}
\hline \multicolumn{1}{|c|}{ VARIABLE } & Sandys.ss & Cahyanirynn & Ria Ricis & Jharna Bhagwani & Saalhaerid \\
\hline LIKE & 176,000 & 119,200 & 93,890 & 98,100 & 168,000 \\
\hline VIEWS & $1,800,000$ & $1,309,000$ & $1,060,000$ & $1,650,000$ & $1,700,000$ \\
\hline
\end{tabular}

Sumber : Pengolah Data Excel

Pada akun TikTok terdapat 17 rasio yang relevan digunakan untuk mengukur kredibilitas pada masing-masing artis. Namun pada penelitian kali ini hanya berfokus untuk menghitung Video views to Video like Ratio. Untuk menghitung kredibilitas dari masing-masing akun TikTok setiap Artis, peneliti menghitung dengan cara : variabel 1 akan dibagi dengan variabel 2, sehingga ditemukan hasil analisisa dari rasio tersebut.

TABEL RATIO

\begin{tabular}{|c|c|c|c|c|c|}
\hline RATIO & $\begin{array}{c}\text { Sandys.s } \\
\text { S }\end{array}$ & Cahyanirynn & Ria Ricis & $\begin{array}{c}\text { Jharna } \\
\text { Bhagwani }\end{array}$ & Saalhaerid \\
\hline Video Views to Likes Ratio & 10 & 11 & 11.28980722 & 16.81957187 & $\begin{array}{c}10.1190476 \\
2\end{array}$ \\
\hline
\end{tabular}

Sumber : Pengolah Data Excel

Video views to Video like Ratio memiliki karakteristik yang tinggi, artinya semakin tinggi nilai yang dihasilkan maka semakin baik kredibilitas dari performa akun tersebut. Untuk memberikan peringkat pada masing-masing Artis tik tok, peneliti memberikan angka 5 kepada vendor yang mendapatkan nilai tertinggi dan angka 1 untuk vendor smartphone yang mendapatkan nilai terendah. Berikut merupakan tabel urutan nilai yang dihasilkan oleh masing-masing Artis Tik Tok.

TABEL PERINGKAT

\begin{tabular}{|c|c|c|c|c|c|}
\hline & & & & \\
kakteristik & Sandys.ss & Cahyanirynn & Ria Ricis & Jharna Bhagwani & Saalhaerid \\
\hline Tinggi & 1 & 3 & 4 & 5 & 2 \\
\hline
\end{tabular}

Dari Tabel Nilai Rasio Akun TikTok 5 artis dengan followers terbanyak, dapat simpulkan bahwa Jharna Bhagwani mendapatkan nilai tertinggi untuk rasio Video Views to Video Like. Sedangkan akun TikTok Sandys.ssi mendapatkan nilai terendah untuk rasio ini. Jadi, pada penelitian ini 
Jharna Bhagwani memiliki kredibilitas performa yang lebih baik dibandingkan dengan artis tik tok yang lainnya.

\section{* KESIMPULAN}

Tujuan dari penelitian ini adalah mengetahui kredibilitas performa dari akun TikTok 5 Artis dengan followers terbanyak di Indonesia menggunakan Video view to Video like Ratio.5 Artis tik tok tersebut diantaranya : Sandys.ss, Cahyanirynn, Ria Ricis, Jharna Bhagwani, dan Saalhaerid. Dari kelima artis tersebut dapat disimpulkan bahwa :

- Peringkat 5 adalah = Jharna Bhagwani

- Peringkat 4 adalah $=$ $\underline{\text { Ria Ricis }}$

- Peringkat 2 adalah $=$ Saalhaerid

- Peringkat 3 adalah = Cahyanirynn

- Peringkat 1 adalah = Sandys.ss 


\section{DAFTAR PUSTAKA}

Akademi Komunikasi BSI Jakarta, S. (2018). Pemanfaatan Aplikasi Tiktok Sebagai Personal Branding Di Instagram (Studi Deskriptif Kualitatif Pada Akun @bowo_allpennliebe). Jurnal Komunikasi, 9(2), 176-185. http://ejournal.bsi.ac.id/ejurnal/index.php/jkom

Oktaheriyani, D., Wafa, M. A., \& Shadiqien, S. (2020). Analisis Perilaku Komunikasi Pengguna Media Sosial TikTok (Studi Pada Mahasiswa Fakultas IImu Sosial dan IImu Politik UNISKA MAB Banjarmasin ). Jurnal IImu Sosial Dan IImu Politik, 7-52. http://eprints.uniska-bjm.ac.id/id/eprint/3504

Akademi Komunikasi BSI Jakarta, S. (2018). Pemanfaatan Aplikasi Tiktok Sebagai Personal Branding Di Instagram (Studi Deskriptif Kualitatif Pada Akun @bowo_allpennliebe). Jurnal Komunikasi, 9(2), 176-185. http://ejournal.bsi.ac.id/ejurnal/index.php/jkom

Oktaheriyani, D., Wafa, M. A., \& Shadiqien, S. (2020). Analisis Perilaku Komunikasi Pengguna Media Sosial TikTok (Studi Pada Mahasiswa Fakultas IImu Sosial dan IImu Politik UNISKA MAB Banjarmasin ). Jurnal IImu Sosial Dan IImu Politik, 7-52. http://eprints.uniska-bjm.ac.id/id/eprint/3504 